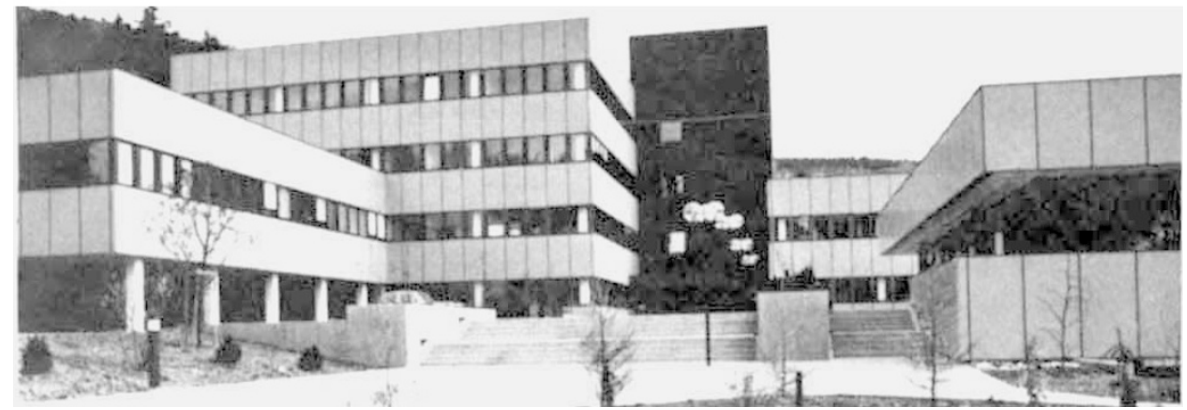

\title{
European Molecular Biology
}

\section{Peter Newmark attends the opening of a new cooperative research venture}

THE European Molecular Biology 1 Laboratory (EMBL) in Heidelberg has become an official fact. $\mathrm{Dr} \mathrm{V}$. Hauff, the West German Minister for Research and Technology, inaugurated the laboratory on 5 May. Sir John Kendrew, Director-General of EMBL, said he was delighted that at last the laboratory was "no longer just an item on the agenda of some boring intergovernmental meeting."

EMBL has one central laboratory, ten minutes drive from Heidelberg town, and two additional outstations, one at DESY in Hamburg, and the other at the Institut Laue-Langevin in Grenoble. The central laboratory will eventually contain about 90 scientific staff (including engineers) but not all of them have yet been appointed. There is also a considerable number of "fellows"-mainly post-docs who bring their own funds-and visiting scientists. The laboratory is loosely split into three divisions: cell biology, biological structures and instrumentation. Only in the latter is there a substantial number of positions still to be filled. What little room is left elsewhere is strongly rumoured to be reserved for the arrival during 1979 of Professor K. and $\operatorname{Dr} N$. Murray on a three-year secondment from Edinburgh University and of Professor J.-E. Edstrom from the Karolinska Institute.

The seeds of EMBL (known by its inhabitants as ee-em-be-el) were sown in 1962- not by biologists but by physicists. Both Sir John Kendrew and Professor E. C. Slater (President of the EMBL Council) paid tribute to Victor Weisskopf, then Director of CERN and a Viennese American, and the late Leo Szilard-a Hungarian American-who between them hatched the idea that European biologists should have a counterpart to the physicist's CERN. Their idea was received with enthusiasm by European molecular biologists, including Sir John, who were concerned at the "brain drain" to the US, and by those committed to greater European collaborations. In 1963 a group of interested scientists formed the European Molecular Biology Organisation (EMBO) to further their aims which included not only a laboratory, but also fellowships, training courses and research grants. Only the last remains to be achieved.

For two years from 1963 EMBO pursued its hopes with, according to Professor Michael Sela head of the Weizmann Institute, their stationery and stamps paid for by Israel. Israel has ever since counted as being in the "European Area", at least when it comes to molecular biology. In 1965 the Volkswagen Foundation provided the first substantial funding that allowed EMBO to go into action with fellowships and training. By 1970 a proper intergovernmental organisation, the European Molecular Biology Conference $(E M B C)$ had been formed by the governments of 13 countries which proceeded to fund EMBO and to consider the setting up of EMBL. This began its formal existence in 1974. Sir John Kendrew was appointed in 1975 and the laboratory is now supported financially by ten of the member states of EMBC.

The EMBL is now governed by a Laboratory Council and EMBC no longer has any legal responsibility for EMBL. The joint secretariat of both EMBC and EMBO (which is also a separate entity with its own funds) has its offices in the EMBL at Heidelberg.

With its ancestry in CERN it is not surprising that EMBL has adopted its conditions of appointment and advancement from its senior relative. That means that initial appointments are for a maximum of three years, with the possibility of renewal for a maximum of nine years or of tenure at any stage. So far a few people have reached the first three-year renewal period, not all successfully, but no one has yet been given tenure. "It is something that I shall restrict and resist," Sir John Kendrew told Nature. Sir John wishes to maintain the flexibility which, he feels, is so scarce elsewhere in

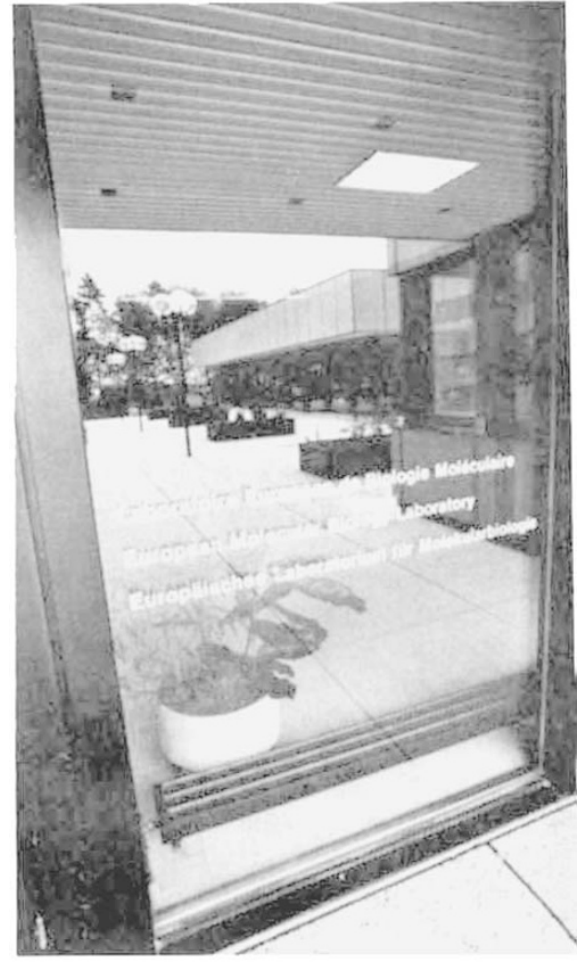

Above: the laboratory and its main entrance, spelling out European cooperation. Top right: EMBL's scanning transmission electron microscope in action. Right: West Germany's Dr Hauff at the opening ceremony and (far right) in conversation with the director-general Sir John Kendrew

Europe. He would, however, be prepared to grant tenure to any scientist of "senior status" but none has yet been appointed-except for Professor L.eo de Maeyer, who has just taken up the position of Head of the Division of Instrumentation. But even this appointment is limited to a three-year secondment from the University of Louvain.

Professor de Maeyer's arrival nevertheless heralds the real effort to establish the central feature of EMBL. From the beginning it was appreciated that EMBL should offer, wherever possible, facilities that would exceed the capabilities of any member nation. And it was in instrumentation that that aim was seen to be most achievable. Paradoxically this central feature is the last to get going since it is only with the completion of the central laboratory that the necessary space and stability has been found. For the present, instrumentation centres on the development of a scanning transmission electron microscope, computers and computer graphics, and synchrotron radiation monitors for the Hamburg outstation. The expansion of the instrumentation division will probably focus on the development of cell sorters, other microanalytical methods, and X-ray detectors. Sir John Kendrew told Nature that he intended to establish a committee that would help determine the instrumentation needs of member 


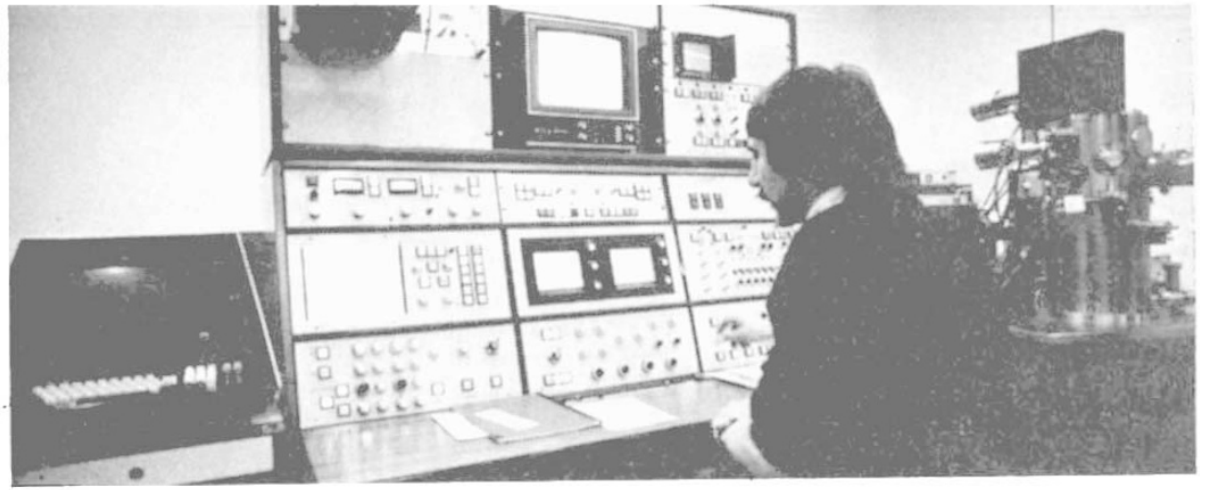

\section{China encourages school science}

Developments in China continue to reflect the new emphasis on education and science. At the end of April, a month after the science conference, the Chinese Ministry of Education organised a national conference on educational work. In the opening speech, Teng Hsiao-ping repeated Chairman Hua's call to train a mammoth contingent of working class intellectuals and to raise the scientific and cultural
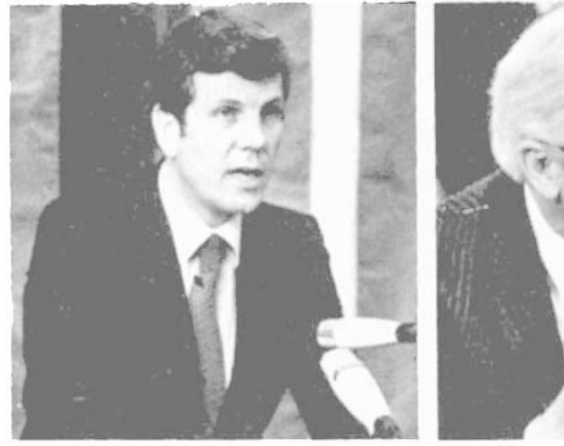

nations. He said it was also possible that instruments would be developed for commercial exploitation with royalties going to EMBL.

The other major feature of EMBL which may never be matched in Europe is its high containment recombinant DNA facility. This was added to the plans of EMBL in 1976 and is now nearing completion. It occupies a separate building of $700 \mathrm{~m}^{2}$, which consists of a series of normal open laboratories and offices separated from a series of high containment laboratories by a range of showers and autoclaves through which all personnel and equipment have to pass. The high containment facilities are not expected to become operational before the end of 1978 , in part because the German government has only just adopted its guidelines for recombinant DNA research. In the meantime staff are being specially trained and a committee is being established to assess priorities for use of the laboratories by visiting and staff scientists. Most of the latter have recently taken up residence at EMBL.

Still under discussion is the possibility of setting up courses in training in recombinant DNA techniques, and the question of the extent to which visiting scientists will be allowed to carry out their own experiments rather than entrust them to EMBL technicians. Despite some local antagonism to the laboratory ("The Monster in the City Woods", according to a Janurary issue of the student paper Heidelberger Rundschau), it is anticipated that P4 experiments will be smoothly under way within a year.

The EMBL does not have its own lecture theatre suitable for gatherings

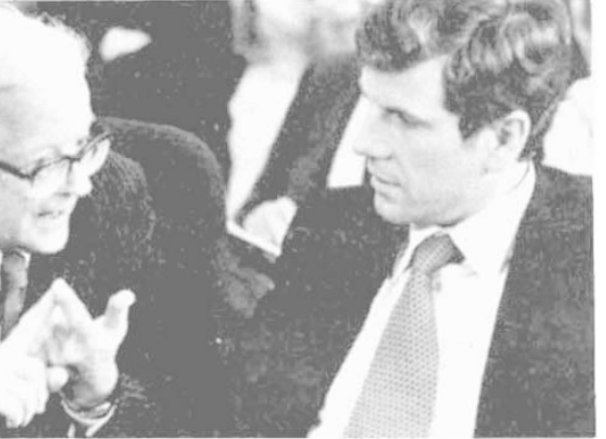

as large as the 200 people who attended the inauguration for which it made use of the facilities of the Max Planck Institute für Kernphysik (nuclear physics) next door. It does, however, have an ample canteen and a large library. It did not escape my attention that the longest complete run of a journal on display in the library was that of Nature. It seemed very fitting for the European Molecular Biology Laboratory that their Nature started with that 1953 volume which contained Watson and Crick's "A Structure For Deoxyribose Nucleic Acid."

The inauguration ceremony was attended by some 200 dignitaries including Dr Hauff, the Ministers of Research of Austria, France and Sweden and many eminent scientists who have acted or still serve as consultants, advisers or members of the Laboratory Council. Dr Hauff, who was a last minute replacement for Dr W. Scheel, President of West Germany, detained by the state visit of $\mathrm{Mr}$ Brezhnev, used the occasion to deliver a remarkably strong statement in support of the freedom of scientific investigation. Science, he said, was an integral part of the spiritual and intellectual freedom that was essential for the survival of a democratic state. The state should not pander to that group of sceptics among the educated strata who wished the state to intervene in the course of scientific investigation. Only when that course departed from the intellectual search for scientific truth to impose itself upon society did $\mathrm{Dr}$ Hauff believe that the state should consider setting limits. As an example of that he cited research on recombinant DNA. levels of the entire nation.

Attention was not to be confined to higher education, Teng said. The scientific content of both primary and secondary school curricula was to be increased. Furthermore, differences in academic ability were no longer to be covered up. Special training of the talented could be combined with broad educational opportunities and students treated differently, so long as the aim remained the creation of conditions for every individual to advance and not the suppression of some for the benefit of others.

Education as a whole was to keep pace with the needs of agriculture and industry, and state departments would work together to integrate the educational programme into the framework of the national economy. Finally, Teng said, the country's nine million teachers held the key to success. They should be respected by their pupils, while they themselves should continue to improve themselves politically and professionally, making full use of postexperience courses, new reference materials, modern teaching aids, radio and television.

Another significant development has been in the Kwangming Daily, one of the three national newspapers published in Peking, which since 1 May has devoted most of its issues to scientific and educational coverage.

And from the province of Anhwei comes the news that, of the 700 new students starting at the Chinese Scientific and Technological University, 92 are under 16. They are students who, with the help of friends and teachers, have progressed well beyond formal levels of education through self-study.

T. B. Tang

\section{Core curriculum}

$I_{N}$ a decision likely to have implications for university courses across the USA, the faculty of Harvard University voted last week to accept a new "core curriculum"-including a course in scientific methodology and an obligatory test of mathematical competence-to be taken by all undergraduates. 